Original Article

\title{
The Influence of Exercise on an Unstable Surface on the Physical Function and Muscle Strength of Patients with Osteoarthritis of the Knee
}

\author{
Chan-Woo Nam, MS ${ }^{1)}$, Kyoung Kim, PhD ${ }^{1)^{*}}$, Hae-Yong Lee, MS ${ }^{1)}$ \\ 1) Department of Physical Therapy, Graduate School of Physical Therapy, Daegu University: 201 \\ Daegudae-ro, Gyeongsan-si, Gyeongsangbuk-do, Republic of Korea
}

\begin{abstract}
Purpose] This study investigated the influence of exercise on an unstable surface on ROM of the knee, muscle strength and the physical function of patients with osteoarthritis of the knee. [Subjects] The subjects were 30 patients diagnosed with degenerative osteoarthritis of the knee, they were divided into an experimental group $(n=15)$ and a control group $(n=15)$. [Methods] The experimental group performed exercise using an aero step XL (TOGU, Germany) 3 times a week, for 6 weeks. A control group performed the same exercise on a stable surface and without aero step XL. [Results] After the intervention, the experimental group showed statistically significant improvements in active knee flexion, knee joint manual muscle test (MMT), knee joint MMT hamstring and WOMAC score. [Conclusion] Exercise on the unstable surface improved the symptoms of patient with osteoarthritis. Exercise on an unstable surface might be helpful for improving the muscle strength and alignment of lower extremities as well as improving physical function related to the knee joint.
\end{abstract}

Key words: Osteoarthritis, Manual muscle test, Range of motion

(This article was submitted Mar. 10, 2014, and was accepted Apr. 21, 2014)

\section{INTRODUCTION}

The growing number of old people has been recognized as a worldwide problem and the incidence of chronic elderly patients is also on the rise. The elderly population forms $10 \%$ of the general population in developed countries. The elderly population of South Korea rose above $7 \%$ of the whole population in 2000 , and has continued rising, passing $9.5 \%$ in 2006. It is expected to be more than $20.8 \%$ in 2026 , when South Korea will become a super-aged society ${ }^{1)}$.

Osteoarthritis is one of the most common disease causing disability and functional problems. It is a clinically important disease which leads to limitation of joint range of mition (ROM), muscle weakness and functional impairments. It is caused by damage to the articular cartilage which affects weight bearing in activities of daily living (ADL) and gait pattern ${ }^{2,3)}$.

Osteoarthritis of the knee is a kind of inflammatory disease of the articular surfaces and it is caused by impairments and abrasion of articular cartilage. That is, it is caused by mechanical and biological factors related to abnormality of the degenerative process affecting the extracellular matrix and cartilage cells between articular cartilages ${ }^{4}$. Medication for the improvement of functional ability is known to

*Corresponding author. Kyoung Kim (E-mail: kykim257@, hanmail.net)

(C2014 The Society of Physical Therapy Science. Published by IPEC Inc. This is an open-access article distributed under the terms of the Creative Commons Attribution Non-Commercial No Derivatives (by-ncnd) License $<$ http://creativecommons.org/licenses/by-nc-nd/3.0/>. be effective for pain relief and improvement of symptoms, but there is a possibility of side effects or overuse. Physical therapy for osteoarthritis includes thermal therapy, photo therapy, electrotherapy, exercise therapy, and manual therapy. These therapies can reduce pain and side effects as well as increase muscle strength, endurance and coordination. Although medication and surgery are effective for pain relief and improvement of symptoms, there is also the possibility of the side effects. For this reason, physical therapy is often selected to treat osteoarthritis ${ }^{5}$.

Exercise therapy has recently become popular. It can improve the general function of the body and activities of daily living by enhancing the range of motion (ROM) and muscle strength of patients ${ }^{6}$. Moreover, it is an effective way for physical therapists to manage osteoarthritis, aiming to stabilize the knee joint and $\mathrm{ADL}^{7}$ ). This study investigated the influence of exercise on an unstable surface on ROM of the knee, muscle strength and the physical function of patients with osteoarthritis of the knee.

\section{SUBJECTS AND METHODS}

\section{Subjects}

The subjects were 30 osteoarthritis patients randomly recruited at J orthopedic clinic after diagnosis by doctors. The inclusion criteria were: an age over 60 years, Kellgren-Lawrence $(\mathrm{K} / \mathrm{L})$ grade $>2$, not currently exercising, and ability to understand the exercise. Subjects who had received surgery on the knee joint were excluded. The subjects were randomly divided into two groups, an experimental group and a control group. Approval for this research was obtained from 
Table 1. General characteristics of the subjects (Mean \pm SD)

\begin{tabular}{lcc}
\hline & $\begin{array}{c}\text { Experimental } \\
\text { group }(\mathrm{n}=15)\end{array}$ & $\begin{array}{c}\text { Control group } \\
(\mathrm{n}=15)\end{array}$ \\
\hline Age (year) & $64.9 \pm 6.8$ & $63.7 \pm 5.6$ \\
Weight $(\mathrm{kg})$ & $60.6 \pm 9.7$ & $60.3 \pm 9.5$ \\
Height $(\mathrm{cm})$ & $155.5 \pm 6.4$ & $154.2 \pm 7.1$ \\
History $($ month) & $72.9 \pm 13.4$ & $75.7 \pm 25.7$ \\
Gender $(\mathrm{M} / \mathrm{F})$ & $7 / 8$ & $5 / 10$ \\
\hline
\end{tabular}

the local Research Ethics Committee. This experiment was conducted after explaining the contents and purpose of this study to the subjects and receiving their consent.

\section{Methods}

The experimental group performed exercises using an aero step XL (TOGU, Germany) 3 times a week, for 6 weeks. The aero step was developed by TOGU and it is an effective tool for promoting stability in rehabilitation. It can be used not only by patients with musculoskeletal and central nervous system diseases, but also for body building and fitness. It is about $8 \mathrm{~cm}$ in height and consists of two parts. It has been reported that this equipment enhances balance, muscle strength, maintenance of posture, and flexibility during exercises in the standing position ${ }^{8)}$.

After setting up the unstable surface, the subjects were told to stand with their feet at shoulder width on the aero step. Then, they flexed their knee joints, keeping their knees vertically above their toes. After maintaining the flexed posture for 5-10 seconds, the subjects were allowed to extend their knees and hip. This exercise was repeated in 3 one-minute sets, with a one-minute break between each set. Then, the subjects were instructed to step on and off the aero step repeatedly and alternately with their lower limbs in 3 one-minute sets with a 1-minute break between sets. The control group performed the same exercises but on a stable surface without the aero step.

The manual muscle test (MMT) is a convenient tool for evaluating the muscle strength and level of impairment. Muscle strength is rated from 0 to 5 according to the muscle performance against resistance ${ }^{9}$.

This test is widely used because it is easy and simple to conduct. Agonist muscles are the target of this test, and if there is any pain in the muscle, pain and compensatory actions need to be eliminated ${ }^{10)}$.

The ROM test is used to evaluate the mobility of patients limbs. It is used to determine the range of motion without pain. In this study, a standard goniometer was used during the active ROM test. To measure knee flexion, the stationary arm of the goniometer was placed on the middle of the greater trochanter, and the moving arm was placed in line with the lateral malleolus and the head of the fibula during active movement by the subjects. The measurements were performed three times and the mean value was used for statistical analysis ${ }^{11)}$.

The Western Ontario and McMaster Universities (WOM$\mathrm{AC}$ ) index is widely used to evaluate the physical function of pelvic and knee osteoarthritis cases. It is a very effec-
Table 2. Comparison of angle, MMT, and K-WOMAC in the experimental group $(\mathrm{Mean} \pm \mathrm{SD})$

\begin{tabular}{lcc}
\hline & Pre-test $(\mathrm{n}=15)$ & Post-test $(\mathrm{n}=15)$ \\
\hline Active knee flexion* & $111.33 \pm 6.67$ & $112.66 \pm 6.23$ \\
Knee joint MMT quadriceps* & $2.80 \pm 0.41$ & $4.53 \pm 0.52$ \\
Knee joint MMT hamstring* & $2.93 \pm 0.26$ & $4.13 \pm 0.52$ \\
K-WOMAC score* & $17.98 \pm 4.07$ & $13.68 \pm 3.19$ \\
\hline
\end{tabular}

${ }^{*} \mathrm{p}<0.05$, Knee flexion $\left(\right.$ angle $^{\circ}$ ), MMT=Manual muscle test, MMT score, K-WOMAC $=$ Korean-Western Ontario and Mc-

Master Universities osteoarthritis index score

tive tool for the measurement of clinical change and joint condition $^{12)}$. This tool evaluates the problems with ADL caused by abnormal symptoms in patients with osteoarthritis, and has three item: pain, rigidity and physical function. The Korean-WOMAC Index, which has been modified for Korean lifestyles, was used in this study. The K-WOMAC Index is divided into sub-items of pain, rigidity and physical function. A higher score indicates more difficulty with ADL, and a lower score indicates easier performance of ADL. Subjects were given a score of 1 to 5 according to their performance and the mean value was used for statistical analysis in this study ${ }^{13}$.

SPSS for Windows (version 20.0) was used for statistical analysis in this study. To investigate the general characteristics of subjects, the $\chi^{2}$ test and the independent ttest were used. The paired t-test was used to evaluate the changes between before and after the intervention in both the experimental and control groups. For comparison of the pretest-posttest changes in values between the experimental and control groups, the independent t-test was used with a significance level of 0.05 .

\section{RESULTS}

There were no significant differences in the general characteristics of the experimental and control groups $(\mathrm{p}>0.05)$ (Table 1).

The pre-test and post-test values of the experimental group showed statistically significant differences in active knee flexion, knee joint MMT, knee joint MMT hamstring and WOMAC score $(\mathrm{p}<0.05)$ (Table 2).

The pre-test and post-test values of the control group showed statistically significant differences in the knee joint MMT, and knee joint MMT (hamstring) and WOMAC score $(\mathrm{p}<0.05)$ (Table 3$)$.

The independent samples t-test the experimental and control groups in the pretest-posttest changes in the knee joint MMT and WOMAC score $(\mathrm{p}<0.05)$ (Table 4).

\section{DISCUSSION}

This study investigated the influence of exercises on stable and unstable surfaces on the knee joint ROM, physical function and muscle strength of patients with osteoarthritis of the knee.

Of the many movements of the body needed for ADL, the movements of the lower extremities are related to gait 
Table 3. Comparison of angle, MMT, and K-WOMAC in control group (Mean $\pm \mathrm{SD})$

\begin{tabular}{lcc}
\hline & Pre-test $(\mathrm{n}=15)$ & Post-test $(\mathrm{n}=15)$ \\
\hline Active knee flexion & $110.00 \pm 7.56$ & $110.80 \pm 6.05$ \\
Knee joint MMT quadriceps* & $2.80 \pm 0.41$ & $3.86 \pm 0.64$ \\
Knee joint MMT hamstring* & $2.73 \pm 0.46$ & $3.80 \pm 0.68$ \\
K-WOMAC score* & $18.00 \pm 4.62$ & $16.67 \pm 3.75$ \\
\hline
\end{tabular}

${ }^{*} \mathrm{p}<0.05$, Knee flexion (angle ${ }^{\circ}$ ), MMT=Manual muscle test, MMT score, K-WOMAC $=$ Korean-Western Ontario and McMaster Universities osteoarthritis index score

performance. Especially, knee joint movement is involved in many activities of daily living. For this reason, osteoarthritis commonly occurs in the knee and pelvic joints which are responsible for weight bearing ${ }^{14)}$. The target population of this study was elderly persons with osteoarthritis, especially of the knee joint. If there is a problem in the knee joint, gait is easily impaired in activities of daily living such as stair-climbing, sit-to-stand and standing ${ }^{15)}$.

The lower limb strength of patients with early phase osteoarthritis is known to be weaker than that of women without any disease. Cartilage problems in the early phase of osteoarthritis being with weakness in the lower extremities, and ultimately result in pain. It is reported that intervention for the improvement of lower muscle strength in early osteoarthritis is successful at minimizing and preventing decrease of body function and muscle weakness ${ }^{16)}$.

Many therapists have studied the effects of manual therapy and exercise therapy on pain and functional impairment in adults with osteoarthritis of the pelvis or knee ${ }^{17)}$. According to those studies, exercise therapy not only increased or maintained muscle strength, but also improved ROM and flexibility of the joint. In addition, it has also been reported that nutrition supplied to the joints prevented impairment, resulting in the maintenance of body function ${ }^{18)}$.

Lee ${ }^{19)}$ suggested that exercise on an aero step is an effective at enhancing muscle strength because it facilitates the somatosensory, vestibular and visual systems, related to maintaining the posture, without stressing the patients. Moreover, it was found in a previous study, that the muscle strengths of the ankle and knee joints were increased after exercise on an unstable surface ${ }^{20}$. Based on these results, we consider that exercise on an unstable surface has a positive effect on the body function and muscle strength of patients with osteoarthritis.

In a previous study of the long-term effects of exercise, it was found that the effectiveness of exercise on pain and physical function decreased with time after the training period. This indicates the need to investigate the long-term effects of exercise. Thus, recent studies have emphasized the importance of methods for maintaining a healthy state ${ }^{21)}$, and have investigated the relationships among pain, physical function and self-awareness of patients ${ }^{22)}$.

Exercise therapy has a positive effect on osteoarthritis which decreases by with time, ultimately disappearing. Thus, future studies need to focus on finding better ways to decide the optimal exercise period for lasting effectiveness.

This study had several limitations. The number of sub-
Table 4. Comparison of the improvements shown by the experimental and control groups (Mean \pm SD) (Unit: )

\begin{tabular}{lcc}
\hline & $\begin{array}{c}\text { Experimental } \\
\text { group }(\mathrm{n}=15)\end{array}$ & $\begin{array}{c}\text { Control group } \\
(\mathrm{n}=15)\end{array}$ \\
\hline Active knee flexion & $-1.33 \pm 2.29$ & $-0.80 \pm 2.70$ \\
Knee joint MMT quadriceps* & $-1.73 \pm 0.46$ & $-1.06 \pm 0.59$ \\
Knee joint MMT hamstring & $-1.20 \pm 0.56$ & $-1.06 \pm 0.96$ \\
WOMAC score* & $4.30 \pm 1.57$ & $1.33 \pm 1.56$ \\
\hline
\end{tabular}

${ }^{*} \mathrm{p}<0.05$, Knee flexion $\left(\right.$ angle $^{\circ}$ ), MMT=Manual muscle test, MMT score, K-WOMAC $=$ Korean-Western Ontario and McMaster Universities osteoarthritis index score

jects was relatively small, thus, it is difficult to generalize the results. Furthermore, 6 weeks is a relatively short period for evaluating the long-term effects of exercise. Thus, studies focusing on the long-term effects to evaluate the relationship between the results and clinical application, are needed.

Exercise using unstable surface improved the symptoms of patient with osteoarthritis but it was not significant between groups. We think that exercise on an unstable surface might be helpful for improving the muscle strength and alignment of the lower extremities as well as positively affecting physical function related to the knee joint. Further studies to develop advanced exercise programs will be needed.

\section{REFERENCES}

1) STATISTICS KOREA: 2010 Elderly Statistics.2010, http://www.nso.go.kr.

2) Davis MA, Ettinger WH, Neuhaus JM, et al.: Knee osteoarthritis and physical functioning: evidence from the NHANES I Epidemiologic Followup Study. J Rheumatol, 1991, 18: 591-598. [Medline]

3) Knoop J, Steultjens MP, van der Leeden M, et al.: Proprioception in knee osteoarthritis: a narrative review. Osteoarthritis Cartilage, 2011, 19: 381388. [Medline] [CrossRef]

4) Mollenhauer JA, Erdmann S: Introduction: molecular and biomechanical basis of osteoarthritis. Cell Mol Life Sci, 2002, 59: 3-4. [Medline] [CrossRef]

5) Han TR, Bang MS: Rehabilitation medicine, 3rd ed. Seoul: Kunja, 2008.

6) Smidt N, de Vet HC, Bouter LM, et al. Exercise Therapy Group: Effectiveness of exercise therapy: a best-evidence summary of systematic reviews. Aust J Physiother, 2005, 51: 71-85. [Medline] [CrossRef]

7) Zhang W, Moskowitz RW, Nuki G, et al.: OARSI recommendations for the management of hip and knee osteoarthritis, part I: critical appraisal of existing treatment guidelines and systematic review of current research evidence. Osteoarthritis Cartilage, 2007, 15: 981-1000. [Medline] [CrossRef]

8) Lee S, Park J, Lee D: Effects of an exercise program using aero-step equipment on the balance ability of normal adults. J Phys Ther Sci, 2013, 25: 937-940. [Medline] [CrossRef]

9) Wadsworth CT, Krishnan R, Sear M, et al.: Intrarater reliability of manual muscle testing and hand-held dynametric muscle testing. Phys Ther, 1987, 67: 1342-1347. [Medline]

10) Cuthbert SC, Goodheart GJ Jr: On the reliability and validity of manual muscle testing: a literature review. Chiropr Osteopat, 2007, 15: 4. [Medline] [CrossRef]

11) Watkins MA, Riddle DL, Lamb RL, et al.: Reliability of goniometric measurements and visual estimates of knee range of motion obtained in a clinical setting. Phys Ther, 1991, 71: 90-96, discussion 96-97. [Medline]

12) Söderman P, Malchau H: Validity and reliability of Swedish WOMAC osteoarthritis index: a self-administered disease-specific questionnaire (WOMAC) versus generic instruments (SF-36 and NHP). Acta Orthop Scand, 2000, 71: 39-46. [Medline] [CrossRef]

13) Hwang-Bo G, Bae SS: Study on the correlation of KWOMAC Index (pain, stiffiness, physical function) with knee Osteoarthritic patients. KPNFA, 
2004, 2: 1-12.

14) Zhang Y, Jordan JM: Epidemiology of osteoarthritis. Clin Geriatr Med, 2010, 26: 355-369. [Medline] [CrossRef]

15) Moskowitz RW: Primary osteoarthritis: epidemiology, clinical aspects, and general management. Am J Med, 1987, 83: 5-10. [Medline] [CrossRef]

16) Palmieri-Smith RM, Thomas AC, Karvonen-Gutierrez C, et al.: Isometric quadriceps strength in women with mild, moderate, and severe knee osteoarthritis. Am J Phys Med Rehabil, 2010, 89: 541-548. [Medline] [CrossRef]

17) Abbott JH, Robertson MC, Chapple $\mathrm{C}$, et al. MOA Trial team: Manual therapy, exercise therapy, or both, in addition to usual care, for osteoarthritis of the hip or knee: a randomized controlled trial. 1: clinical effectiveness. Osteoarthritis Cartilage, 2013, 21: 525-534. [Medline] [CrossRef]

18) Miyaguchi M, Kobayashi A, Kadoya Y, et al.: Biochemical change in joint fluid after isometric quadriceps exercise for patients with osteoarthritis of the knee. Osteoarthritis Cartilage, 2003, 11: 252-259. [Medline] [CrossRef]

19) Lee SH: The differences between aero step exercises and weight training on posture, physical fitness, balance, and hormone levels in the elderly. Master's thesis, Ewha Womans University, 2007.

20) Ha NR, Kim MC, Han SK: The Correlation between changes of ankle joint position sense and sway area through unstable surface training. JKIECS, 2013, 8: 1383-1390.

21) Pisters MF, Veenhof C, van Meeteren NL, et al.: Long-term effectiveness of exercise therapy in patients with osteoarthritis of the hip or knee: a systematic review. Arthritis Rheum, 2007, 57: 1245-1253. [Medline] [CrossRef]

22) Pisters MF, Veenhof C, Schellevis FG, et al.: Exercise adherence improving long-term patient outcome in patients with osteoarthritis of the hip and/or knee. Arthritis Care Res (Hoboken), 2010, 62: 1087-1094. [Medline] [CrossRef] 